\title{
PROJECT MANAGEMENT FOR CIRCULAR ECONOMY IN DEVELOPING COUNTRIES USING PROPER POLICIES AND STRATEGIES IN RECYCLING ISSUES. THE CASE OF LEBANON
}

\author{
Reina BOU NEHME ${ }^{a *}$, Cristian-Silviu BANACU ${ }^{b}$, Ghanim Ahmed KAMIL \\ ${ }^{a, b, c}$ Bucharest University of Economic Studies, Romania
}

DOI: $10.24818 / \mathrm{IMC} / 2020 / 03.12$

\begin{abstract}
The paper aims to perform the job of demonstrating and presenting an overview regarding the concept of Circular Economy, along with major emphasis on its presence and need in the developing countries especially. The discussion would follow through the protocol of discussing all the policies and mechanisms that have been adopted or need to be adopted by such developing countries in order to cope up with the economic and environmental problems generally that they are bound to face otherwise, inevitably. The paper specifically focuses on the case of Lebanon, emphasizing the country as an example to further demonstrate the position of the developing countries. Of course, the whole discussion is far from being single dimensional and calls for "multiple aspects and factors to be discussed to be able to entirely comprehend the situation, which is what the paper focuses on. For instance, the phenomenon of maintaining a circular type of economy is highly associated with the concept of waste management, which is one of the major issues the world is currently facing today at a global level. The paper serves to provide a detailed description and overview of this type of economy, how it can prove to be beneficial especially for developing countries like Lebanon, as well all the policies that these mentioned countries need to adopt in order to be successful in the process, along with the obstacles they have to face one way or another.
\end{abstract}

KEYWORDS: recycling, environment, circular economy, developing countries, sustainability, government policies and strategies

\section{INTRODUCTION}

\subsection{Circular Economy:}

The concept of Circular Economy generally expands beyond the horizons of general abilities of comprehensions of a human mind. Zink and Geyer (2017) have described this type of economy as a concept that is built on the idea of generating closed material loops, in order to ultimately aim towards the preservation of the products and materials in the system, hence directly or indirectly leading to gaining maximum efficiency and benefit. The appeal and requirement for this sort of economic system comes from the general thought process aimed towards substituting the lower impact secondary production for primary production that serves to be environmentally intensive in anyway whatsoever. In a nutshell, such an economy will not have any kind of waste and the resources are used continuously. The conceptual diagram of the circular economy is presented below:

\footnotetext{
${ }^{*}$ Corresponding author. E-mail address: reinabounehme@hotmail.com
} 


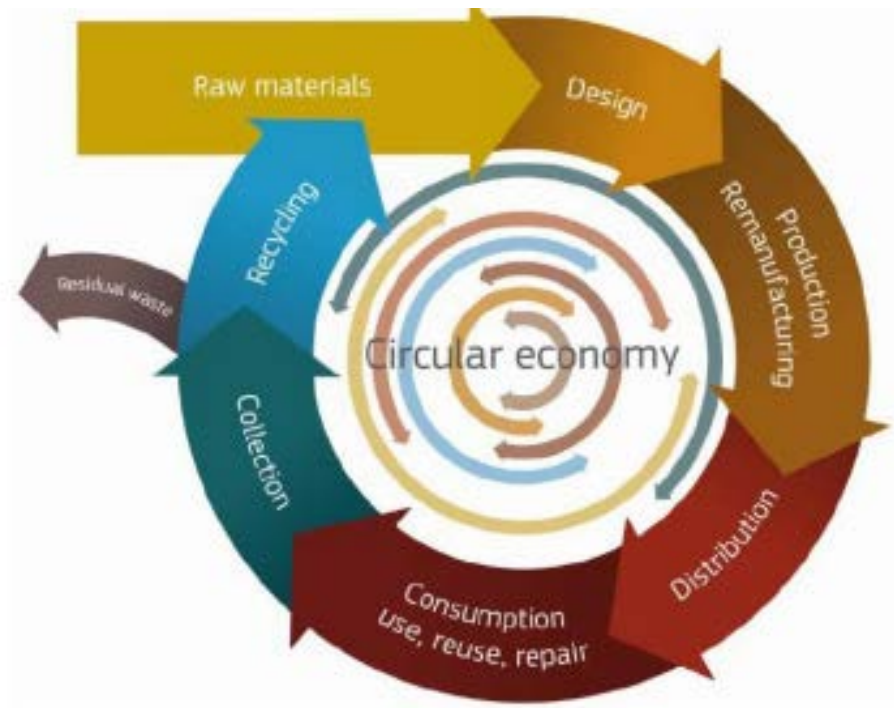

Figure 1: Circular Economy - Conceptual Framework Source: (Wautelet, 2018)

As much as it proves to be extremely beneficial for a multitude of reasons, the process of adopting it and the requirements as well as consequences prove to be incredibly troublesome and problematic at a large scale in most of the cases. As per the explanations that have been provided by Kirchherr et al. (2017), this particular type of economy is generally and frequently associated with certain combinations of feature such as reducing and reusing, as well as recycling activities. It should be understood that Circular Economy is generally found to be more co-related to the concept of economic prosperity for any state. Also, a well-established fact as of this point is that all the stakeholders are interlinked such as various business models used by the company, the consumers that are generally declared or knows how to play their part in this particular type of economy. There is no doubt in the fact that this type of economic system is highly associated directly with the concept of sustainability of a state's matters regarding such agendas. The whole motive of the Circular Economy is to ensure developing and integrating a system that benefits in the production of maximum efficiency rate, with little or no loss. However, Geissdoerfer et al. (2017), have written about how the two concepts of this type of economic system and sustainability might be considered to go hand in hand, that might not entirely be true. Basically, the similarities and the differences between these two concepts somehow happen to remain ambiguous. One of the difficulties regarding all of this would be the fact that the relationship between these two are not explicitly discussed enough so far in the preexisting literature. This serves to on some levels blur the conceptual contours hence somehow affecting the efficacy of the approach in the first place. The Circular Economy, as explained, follows the concept of adopting such policies that are entirely dependent on the concept of recycling, as well as strategies that are among these lines as well. According to Cramer (2020), the implementation of this type of economy is something that takes place gradually and hence evolves with the passage of time. For instance, the transition management cycle provided by Loorbach (2010) could prove to be one of the highly resourceful tactics that need to be referred for a detailed and thorough understanding of what sort of policies and strategies would ultimately help in the transition. The developing countries need to opt for measures that would be implemented in such a way that they encourage the long-term promotion of a Circular system of economy. This would include the formulation of legislation, policies, objective, and so on. All to ultimately provide the developing country the ability and the capability to stand on these policies and strategies and manage to somehow leapfrog their way towards a sustainable system that proves to be not only beneficial but also highly efficient in all regards. It is also important when implementing such a system to manage it effectively and considering this 
change or implementation of policies and strategies towards circular system should be managed as projects. Several project management concepts and strategies can be used to manage effectively this implementation.

\subsection{General Economical State of Developing Countries:}

Evidently, there is a significant as well as incredibly urgent need in developing countries not only in the public sectors but in the non-governmental or private organizations as well to go on with the process of developing some relevant strategies and structures that proceed towards contributing to the phenomenon of social justice, as well as poverty eradication, and stabilization of the economy of the country (Dobers \& Halme, 2009). The general economic state of the developing countries is not entirely reliable and is deeply calling for help in all the ways it possibly can. This level and state of economy does not guarantee any level of suitability and hence there is no assurance of a safe and secure future in all these regards. Of course, one of the ultimatums based on which the general economy of such countries are not doing well is dependent on the type of economy they dwell on, which is the make-take-waste system. This particular system is discussed below in detail to get a better insight.

\subsection{Potential Environmental Consequences of take-make-waste economy system:}

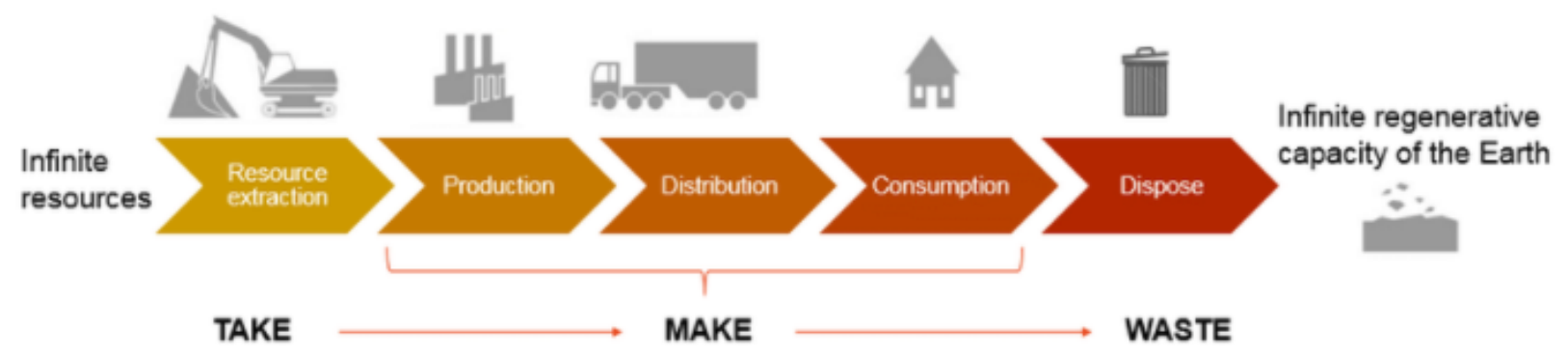

The linear economy-The 'take, make and waste' approach of production

Figure 2: Take-make-waste Approach

Source: Wautelet (2018)

The general concept regarding the take, make and waste approach of economy could be demonstrated very well with the help of this flow chart presented above as explained by Wautelet (2018). This approach focuses on the extraction of the resources, proceeding towards the production and distribution of the required material, and ultimately towards the consumption of them. The process ends by disposing of the waste material and starts with the extraction of resources. It is worth mentioning here that there is no recycling of these products, but instead all of it goes to be disposed of entirely. This is why it is also actively known as a linear cycle, rather than the circular cycle. The main reason for calling it linear cycle is that it is used only once while in circular cycle, it focuses on proceeding towards less waste production and more recycling of resources, hence benefiting the economy in both, short and long term run. Since the linear economy does not rely on recycling of the resources and proceeds with disposing off the finite resources, it only makes sense to understand the implication of the fact that it is not a very suitable approach. This is essentially and especially true for developing countries like Lebanon, which already does not have a vast amount of resources and are desperate to find ways to survive with the less number of resources, and make maximum usage out of them, rather than using them once and having them disposed of. This sort of economy is dependent on the fact that there are plenty of resources to be used and 
disposed of freely. Hence, it is suitable and optimal approach for such developing countries to shift from this linear form of economy to the circular type. According to Sariatli (2017), the transition from linear economy to circular economy is never simple or easy. Contrary to the linear approach, in the circular approach the system that is used is built evidently on the three R's, that is, reduction, reuse and recycling. Unlike in the linear economy, in this approach the material cycles are actually closed ultimately, and waste is not considered as something to be disposed of, but something that is considered as important as a valuable resource itself.

\section{LITERATURE REVIEW}

\subsection{State of Developing Countries with regard to resources}

As explained by Bahl et al. (1984), most of the developing countries across the globe are making tremendous efforts to put an increased pressure on the local governments of these respective states in order to mobilize the resources, keeping the main aim of meeting the recurrent values of operating capital projects in their minds. If one talks about all the issues that third world and developing countries face in the modern global society of twenty-first century it most probably will be the social collective of resources that these countries have and the curse of their non utilization. It is evident that most countries which are still developing and fighting against the evils of poverty, discrimination, sectarian wars, corruption and basic freedom, are also the ones with only a handful of resources on their plates. If one looks more closely, it is easily observable that rather than contributing to freedom, growth, and social peace, rich deposits of oil and minerals have often brought tyranny, oppression, misery, and insecurity to these nations. In one of the researches carried out by Stanford University on mineral utilization worldwide, it was evident that how the countries with more resource pool are the ones that suffer the most with corruption and lack of accountability between rulers and citizens (Wright \& Czelusta, 2003). Also, the risk of civil and sectarian war rises when the countries depend on the export of basic resources and commodities. The question that arises is what can be done to balance this high resource pool and its mindful progressive usage. In last ten years, many of the known developing countries have passed national action plans to ensure the proper usage of resources they have. These plans act on to improve revenue and tax management of these resources. For now, international community, developing countries can only hope that these action plans provide the people in these countries with positive results by the next decade, if not within this one. It is also important to manage the policies and strategies that the governments made. Many governments particularly in the developing countries announce or formulate strategies to better manage the resource and reduce the wastes. In short, they try to shift towards circular economy, however, the implementation remains a question mark. One of the main issues identified is the implementation of the policies and strategies developed. If these strategies are managed in a proper way, then only it would yield positive results. Another important point in the successful implementation of these policies is to consider it as an ongoing process and consciously track it and for this purpose, project management techniques can be very handy.

\subsection{Recycling Capabilities in Developing Countries}

Recycling is the process of converting used things and waste materials into new materials and objects for their re-use. In the modern era of increasing pollution and environmental hazards, this effective process can positively contribute to the decrements of waste materials and pollution on a national and international level as well. Now if one is to specifically observe the recycling capabilities of developing countries, one can easily conclude their ineffectiveness in this matter. Increased plastic usage, dumping of industrial wastage into oceans and overall unhygienic ways of living with minimum to no recycling awareness on individual as well as at national levels have contributed significantly to the global increment of pollution, sea intoxication and ozone depletion. All these have ultimately led these developing countries to face the increased environmental 
apocalypses (Geng \& Doberstein, 2008). Sorting garbage is a relevant topic in many countries as it contributes to environmental protection. But unfortunately, in developing countries this is still an alien topic. There are many reasons behind this and some of the main ones include; the lack of education, poverty, many people living below the living standards, non-serious behavior of leaders of such nations and lack of awareness among common people. Moreover, the government is not leading the process of circular economy which is also not helping the cause (Oliveira et al., 2020). Apart from contributing to the worldwide pollution, not able to recycle things and wastes also lead to the decrease in resources of the country. In a developing country that faces resources related issues, this proves to be yet another hurdle which directly and indirectly causes problems in their path of development. The need of the time for developing countries is proper strategies to ensure the recycling on individual as well as national level and to continue motivating the correct disposal behavior and practices. It has to start from the top and then only it will reach to the bottom level which is the public. If the government is not serious on this matter, then in developing countries, only the general public will not be able to lead and implement (Govindan \& Hasanagic, 2018).

\subsection{The Case of Lebanon}

Before the waste crisis emerged as an issue, the officials of the city relied on the Naameh Landfill in Southern Beirut which had the capacity of two-million-ton to dispose of the wastes. However, the waste crisis came into existence when almost twenty years had passed and the landfill was overflowing with 15 million tons of waste, which was originally meant to sustain the waste for less than half of the existing time span (WOIMA, n.d.). Moreover, every year the waste production rose in the city. Lebanon had been producing more waste than what the country could manage. An estimated 2000 tons of waste is generated in Beirut and Mount Lebanon per day. According to Sarah Abdallah (2020), in July 2015, the Naameh Landfill was finally closed and the city faced a major waste crisis. Being the largest landfill in the city, Naameh bears most of the rubbish produced in the city. According to Mavropoulos (2017), the landfill was shut down due to the dire sanitary conditions, capacity issues and public opposition to unsafe waste disposal. Once it was closed, the authorities could not present an alternative solution effectively at that right time. Waste collection was ceased and the tons of waste produced in the city piled up on the streets instead of going to the landfill. The government had no contingency plan to deal with the waste produced by the residents in the city, and the waste continued to pile up on the streets and riverbanks. The citizens began to protest against the government's inability to provide safe and successful waste disposal strategies, but to no avail. The authorities are still struggling to find viable solutions to the waste disposal issue prevalent in the city. Meanwhile, the waste collectors started dumping rubbish in unauthorized areas which exposed the citizens to severe health concerns. To temporarily collect and store the city waste, two coastal landfills have been built in the North and South Beirut, specifically in Bourj Hammoud and Costa Brava respectively. However, this temporary solution of re-opening Bourj Hammoud landfill is a disaster in itself. The landfill initially originated as an uncontrollable dumpsite back when Lebanon Civil War was underway. The site has not been rehabilitated and continues to be an environmental hazard to the residential areas nearby and the people living around it. The dump-site occupies an area of around 16 hectares with extremely steep side slopes, rising to about $55 \mathrm{~m}$ above sea level. The waste dumped here is already spilling over to the Mediterranean Sea. Per annum, the landfill an estimate of 120,000 tons of waste. The crisis persisting in the city is due to the combination of a multitude of factors. These factors pertain to corruption, poor governance and poor infrastructure which makes sewerage and waste management system extremely fragile and unhealthy. According to Azzi (2017), over the following couple of years, the government started forming committees focusing on environmental safety and waste disposal planning. 


\subsection{Policies regarding the Circular Economy and recycling}

Over the last couple of years, institutions have realized the importance of abandoning linear economic model and adopt sustainable economy policies and strategies. According to Dolinsky and Maier (2015), these policies cause a reduction in the pressure on the environment. They launch actions that escalate waste reduction, promote eco-design, cause a reduction in the greenhouse gases harming the environment, and enable the safe and healthy supply of raw materials. The linear economy model focused on the principle of product waste after use, without devising plans of sustenance prior to use of those materials. Sariatli (2017) declares this kind of economy model ineffective and a failure in protecting the environment. The dire circumstances gave birth to a new economic model that would better sustain the environment and focus on preventing the damage before it occurs. This model called the Circular Economy model entails the prioritizing and planning the use of existing natural resources. The policies related to circular economy are directed towards the reduction, reuse, recovery and recycling of materials and energy. By considering the future use of the existing resources and their by-products, one can use waste as a resource as well and direct it to be incorporated into the production process. The implementation of this kind of economic model presents a plethora of benefits for the environment and society by enabling the prospect of sustainable growth due to reduction in waste production, reduction in energy consumption and reduction in use of resources. The economic aspect of circular economy is correlated to sustainability in the way that it ensures the maximum redirection of products, materials and resources into the production process, reducing the waste and energy consumption and maximizing the time and use of existing resources. According to $\mathrm{Hu}$ et al. (2018), the effective implementation of an effective circular economy model entails the search for more sustainable raw materials and energy resources, the transformation of production processes to more energy-efficient ones, the development and promotion of use of more durable and susceptible products in order to reuse and recycle them in the future, and devising business models which are economically viable and environmentally sustainable. According to Reike et al. (2018), circular economy contributes to the re-industrialization of regional and national territory, converting waste into raw materials for final products as a paradigm of a future business model that helps maintenance of a sustainable environment.

\subsection{Obstacles faced in adopting these policies}

According to Rizos et al. (2016), it is evidently clear to the developing countries that developing such a system of closed-loop would prove to be highly beneficial. So the question comes up that as they are aware of the benefits that the Circular Economy would bring to them, why are they not opting for it? The answer to this question lies in all the obstacles that they have to become capable to implement such a system in their country. The few tactics and mechanism that need to be opted by these developing countries in order to effectively implement this system would include using means such as laws, education systems, and governance in such a way that it encourages the growth of this mindset that supports the awareness regarding the consequences and requirements of this system. The well-known obstacles of not having enough resources and to not be able to be strong financially are the greatest hurdles these nations face with regard to adopting this new closed system of economy. Of course, implementing it, would prove to be beneficial, but to get to the level of implementing itself is too much to cope up with for such countries, as explained in the case study of Lebanon. Moreover, governments think about such actions, but with corruptions high and lack of proper governance make it harder for the government to implement even if they wish to.

\section{METHODOLOGY}

The research paper is based on secondary research with the help of systematic literature review analysis. For this research, both qualitative and quantitative strategies were chosen. Qualitative approach is defined as the set of research techniques in which the data for study is collected or the exploration and inquiry for the data which is relevant to the case under study is made by 
interrogating a relatively small number of respondents and the data that is received is not analyzed. Qualitative study is chosen to receive a more comprehensive perspective on the subject. It is inclined more towards exploring a phenomenon rather than testifying a hypothesis. This perspective is chosen because in this research, the substantiation of the aim of the thesis is achieved by studying and evaluating a real time case study. Quantitative approach is included in this research design because the display of numbers is used to highlight the waste management crisis in Lebanon.

\section{ANALYSIS AND FINDINGS}

\subsection{Case Study of Lebanon}

The generation of waste in Lebanon has increased considerably over past few years. Main factors constibuting to the incerase the waste generation include improvement in the standards of living, influx of refugees from Syria, increased urbanization, and rising levels of population. Lebanon has been suffereing highly with the issues and challenges related to collection, treatment and disposable of overall muncipal waste.Before analyzing the issues and challegnes it is important to identify and explore the important statistics related to waste generation in the country. The MSW (Municipal Solid Waste) generation in Lebanon is around 2.04 million tons (details given in Figure 3).

\begin{tabular}{ll}
\hline Population & 5,600000 Lebanese +2500000 refugees \\
\hline MSW Generation & 2.04 million tons \\
\hline$-\quad$ Urban Areas & $0.95-1.2 \mathrm{Kg} /$ day \\
\hline$-\quad$ Rural Areas & $0.8 \mathrm{Kg} /$ day \\
\hline MSW Generation Growth & $1.65 \%$ per year \\
\hline Medical Waste & 25040 tons/year \\
\hline Industrial Waste & 188850 tons/year \\
\hline Slaughterhouses Waste & 40000 tons/year \\
\hline
\end{tabular}

Figure 3: Statistics about Waste Generation in Lebanon

Source: Abbas et al. (2017)

The breakdown of the composition of MSW is presented in the figure 4 below. However, it is important to highlight here that one of the major challenge in SWM (solid waste managemnet) in Lebanon is that no recent data is available regarding the waste generation (Boswall, 2019).

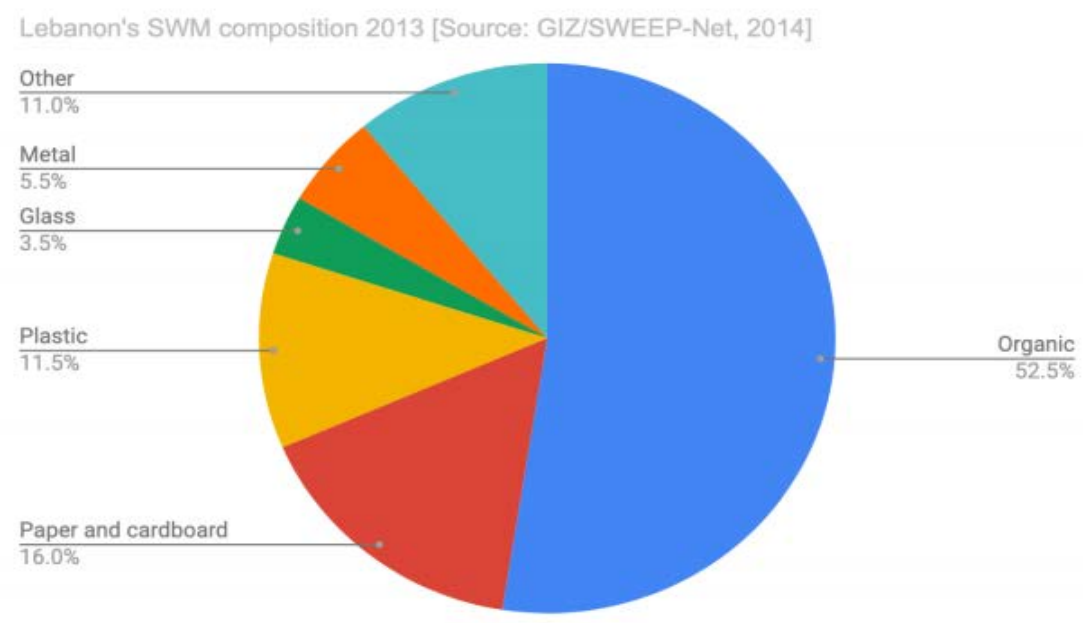

Figure 4: Composition of MSW

Source: Boswall (2017) 
Statistics regarding the disposable of MSW are also old. Around 48\% of the MSW is disposed of in the landfills, around $29 \%$ is dumped openly, 14 to $15 \%$ of this waste is composted, and only $8 \%$ is being recycled (Boswall, 2017; Abbas et al., 2017). Lebanon has been facing serious waste management issues from the start and faced a major waste crisis in 2015. In order to overcome this crisis, the then government of the country came up with waste emergency plan. The same plan is being used till now and there is high need now to modify the plan and come up with SWM that address all important factors and elements. In order to devise an effective and efficient Solid Waste Management (SWM) plan, it is curcial to identify recent statistics. Apart from this, it is also important to understand the waste hierarchy as shown in the figure 5.

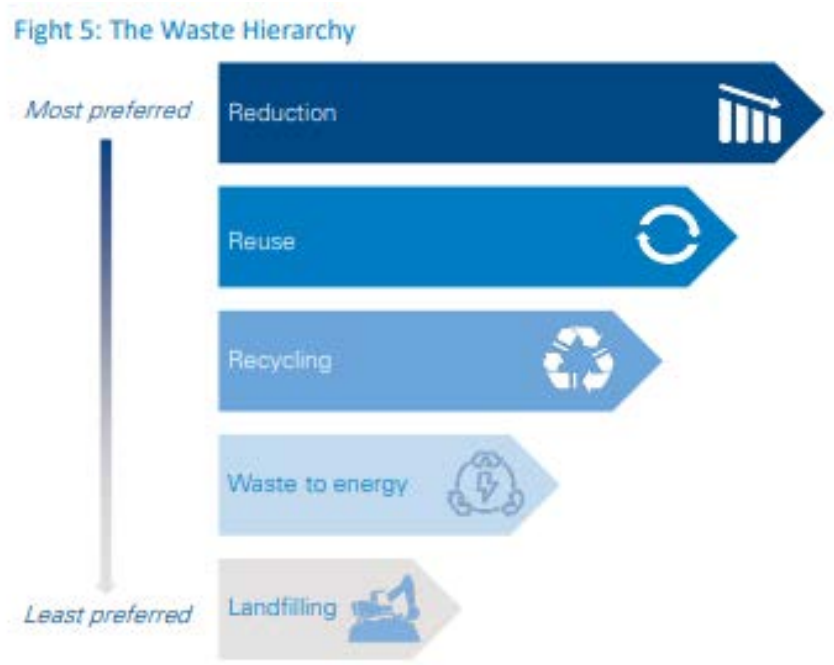

Figure 5: WasteHierarchy

Source: Romboli et al. (2018)

In order to come up with new long term policy it is first important to identify the barriers in the process and overcome these barriers. There are four main barriers to the formulation of effective SWM plan (shown in Figure 6). The first barrier is lack of proper regulations and weak enforcement. Second is unsychnronized efforts and improper planning due to the political conditions of the country. Thid barrier in this regard is that Lebanon is facing a major issue of lack of proper and developed infrastructure. Lastly, the forth barrier is overall social barriers and issues related to compliance.

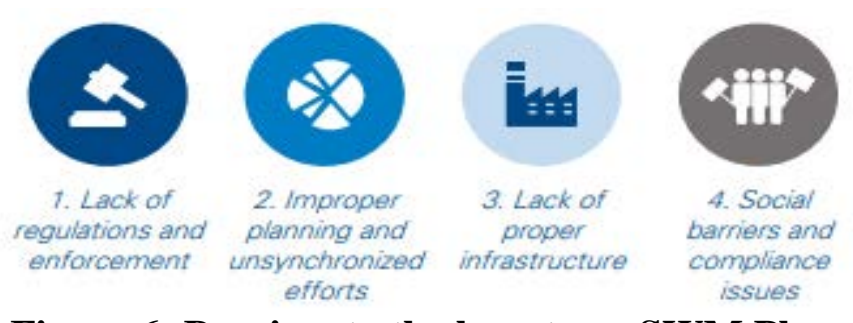

Figure 6: Barriers to the long term SWM Plan

Source: Romboli et al. (2018)

Apart from the barriers, it is also important to identify important stakeholders and understand their impact on the overall process. The invovlement of stakeholders is the main element for the implementation of effective and efficient strategy for SWM. Most important stakeholers in this 
regard is the government of the country. Figure 7 highlights important stakeholders and their roles in the waste management.

\begin{tabular}{|c|c|}
\hline Stakeholder & Main Responsibilities \\
\hline Waste Management Board & Developing waste strategy and authorizing waste management plans \\
\hline Ministry of Environment & $\begin{array}{l}\text { Initiating waste management standards and guidelines and implementing waste } \\
\text { management programs }\end{array}$ \\
\hline Ministry of Interior and Municipalities & $\begin{array}{l}\text { - Participation in the National Strategy and plan and implementation of local waste } \\
\text { management plans } \\
\text { - Establishing/ implementing waste management programs }\end{array}$ \\
\hline Municipalities & $\begin{array}{l}\text { - Participation in the National strategy and plan through the Waste Management Board } \\
\text { - Proposing and implementing local waste management plans for non-hazardous municipal } \\
\text { waste } \\
\text { - Establishing / implementing waste Management programs } \\
\text { - Management of waste collection }\end{array}$ \\
\hline $\begin{array}{l}\text { Council of Development and } \\
\text { Reconstruction }\end{array}$ & $\begin{array}{l}\text { - Assistance in procurement of WM projects upon request } \\
\text { - Assistance in the development of WM plans upon request }\end{array}$ \\
\hline Private Sector / the Public & $\begin{array}{l}\text { - Abiding by laws, regulations and guidelines on waste management } \\
\text { - Prohibition of littering, illegal bumping and burning } \\
\text { - Participation in the National strategy and plan through the Waste Management Board } \\
\text { - Participation in the development and implementation of local waste management plans } \\
\text { - Participation of facility and generator management plans }\end{array}$ \\
\hline
\end{tabular}

Figure 7: Stakeholders and Their Responsibilities

Source: Abbas et al. (2017)

\subsection{Discussion and Recommendations:}

\subsubsection{Discussion and Analysis of Literature:}

According to Lewandowski (2016), big global companies like Google, Renault and Unilever are moving towards the circular economy. This new model promises them huge social, financial and environmental benefits. However this shift can be too risky for small companies. There needs to be a safe paradigm for the shifting of these small businesses and the current method is veey limited in doing that. Thus this research explores the features of Circular Economy using a business model structure. The research revealed two new components of business models in circular economy context; the take back system and adoption factors. Additionally the Triple Fit Model has been identified as an effective mechanism for transitioning to the circular economy. The studies by George et al. (2015) on a theoretical model incorporates circular economy activities. The model constructed uses two types of resources; the recyclable input and the polluting input. Marginal product of recyclable input, the recycling ratio, cost incurring for using polluting resources and the extent of pollution created by it were the factors identified to be affecting economic growth. The results reveal that the environmental pollution cannot be controlled by improving economic growth. It is rather maintained by the rate at which self-renewal for environment is being done. A morphological analysis of 26 current circular economy business models by Lüdeke-Freund et al. (2019) shows that most of the literature presented in this regard suggests similar approaches, refer to the same frameworks or points out the need for consolidation of the present state of the art. This analysis suggests six circular economy business models which can be effective to support the resources flow closing. Refurbishment and remanufactiring, recycling, cascading and repurposing and lastly organic feedstock business patterns were suggested to be employed as potentially efficient circular economy business models. A literature review followed by a similar exercise was done by Schroeder et al. (2019) to explore the extent to which circular economy can be used for sustainable development goals. The circular economy and clean water and sanitation, affordable and clean energy, Life on land, reasonable consumption and prodution are some of the closely related things in sustainable development goals. The research states that circular economy practices can be 
used to achieve large number of sustainable development goals. It also reveals several trade offs between targets, safer working environment, current circular economy practices relating to waste management and provides suggestions for their improvement. According to Sairez-Eiora et al. (2019), there can be six practical approaches to make use of circular economy practices for sustainable development goals. These include adjusting inputs to the system to regeneration rates, adjusting outputs from the system to reabsorption rates, closing the loop of system, maintenance of resources' value within the system, reducing circular economy's size and designing and education for circular economy shall be employed.

\subsubsection{Cicular Economy in Lebanon:}

After analyzing all important varaibles and factors related to the waste management system of Lebanon. It can be proposed that implementing the cicular economy can help in coming up with SWM strategy that can be effective and efficient and can help the economy in reducing its overall waste output and managing its waste effectively.It is crucial to get an understanding of the fact that the shifting towards circular economy or such a sustainable economic system is not something that can take place in a split second, but requires a lot of efforts and time. The steps that need to be taken in order to install this sort of system would include generating awareness, for starters, about this system. The second stop would be to understand the necessity of it. It is indeed true that the circular system of economy is less likely to be considered as compatible with the Current system of the Lebanon. But the shift is necessary nonetheless for a multitude of reasons.The following steps would be those that revolve around the actions that need to be taken to be able to adopt this system. Not only does it call for a development in the sector of industry, but a major development regarding the waste management policies and system is also truly required. Now, the mentioned required development in this waste management system is again not something that can be done overnight, and is instead done on multiple levels and multiple stages which might be as follows.

\section{Generation of Waste:}

The whole scheme and system actually revolves around the concept of waste generation, which is followed by its utilization and end result. Efforts need to be made in order to generally reduce the rate of waste production, as an overall tactic to tackle the issue. The EPR, which stands for Extended Procedure Responsibility, also needs to be taken under notice and ultimately enhanced at more than one levels. The schemes that revolve around the mentioned EPR are those that emphasize on manufacturing of such products that happen to fall under the category of being recyclable or reusable.

\section{Waste Cost Recovery:}

Of course, one of the significant reasons why it is difficult for states like Lebanon to shift to this sort of economy is the finances. This desired mode of economy can never possibly be achieved without going through the process of actually ensuring the sustainibility level generally. At this point it is important to recognize and acknowledge the fact that in order to manage and ensure the sustainability of any system, there is an important requirement to manage the $O M \& D$, which stands for Operation, Maintenance and Development. Clearly, the current legislation and system of the state of Lebanon does not pay any attention to sustaining OM\&D, which sets to be a major drawback as a whole.

Collection of Waste:

The tactics that are being used in the present for the ultimate purpose of collecting the waste need to evidently be redesigned as well as reconsidered, given the current situation. 
Processing of Waste:

The management processes and the system of processing the waste within Lebanon happen to be very basic and generic. In fact, it won't be wrong to pen down that they are highly biased towards labor sorting and segregations. The last-level goal should without a doubt be to develop such a system of waste processing that sets its roots into the grounds of favoring decentralization, in order to enhance robustness as well as sustainibility.Shifting to the Circular Economy is, as mentioned, not a simple or easy step - but is essential for sustainance nonetheless. The whole process should be implemented with an approach that varies slightly than the normal scenarios. This is to say that it should consider the significance of the pragmatic and systematic manners and relies on a gradual shifting that is done in phases, and is considerate towards the current affairs regarding the system and infrastructure of Lebanon.

\section{CONCLUSIONS}

In this research, the concept of Circular Economy, with regard to the developing countries have been discussed. Generally, the aim is to discuss the idea regarding what would be the outcome if the developing countries opted to actually implement such type of economy. Of course, such a discussion must inevitably consist of all the aspects and dimensions regarding it, including those that talk about the policies that every state needs to adopt to be able to proceed and build a sustainable system, as well as the obstacles and hurdles that come in their way. Moreover, the implementation would be like a project, and has to be tracked at regular intervals to ensure better results. The concept of circular economy is new, difficult to attain yet sustainable and largely beneficial for countries to base their economies on. It dwells on the idea of using the 3Rs - Reduce, Recycle, Reuse. This environmental friendly approach would help developing countries to conserve their energy resources more efficiently by reducing the wastage and utilizing the maximal benefits of their energy resources, thereby preventing the masses from running out of their basic needs. A shift from linear to circular economy could be challenging to opt mainly for developing countries with limited resources, but the sustainability and implementation make it harder. However, if implemented, then it would give great results it in the long run. The case study of Lebanon and its history regarding the issues concerning this agenda prove to be beneficial in understanding the whole concept overall. This is referring to the time period when the state of Lebanon, a developing country, was actively producing more waste than it could possibly afford. The consequences of this waste material crisis were uncountable, including those regarding the management issues, unsanitary environment, and toxic substances available to pollute the country, and so on. Not to mention, it took Lebanon significant amount of time as well as tremendous efforts in order to gradually rise above the issue. Their plan included formation of various committees with the sole purpose of managing this environmental crisis. The financial loss cannot even be comprehended. The above analysis thus provides a view of how the circular economy work and different literature produced on it yet has been lacking practicality. Moreover the cost effectiveness of this model and rates and value maintenance in the circular economy business models are highly doubtful which need to be worked on. Also it can help with several sustainable development goals but only if the strategies adopted get more practical aspects to it. This study hence, serves to be an insightful example about how every country across the globe, especially the developing countries, need to opt for policies and strategies that ensure a sustainable ground for them to rest on. This requires providence of a lot of attention to the matter, and development of committees that ultimately only have the major aim of developing such mentioned policies. Hence, Circular Economy is the right way to go in order to build a sustainable environment. 


\section{REFERENCES}

Abbas, I., Chaaban, J. K., Al-Rabaa, A. R., \& Shaar, A. A. (2017). Solid Waste Management in Lebanon: Challenges and Recommendations. Journal of Environment and Waste Management, 4(3), 235-243.

Abdallah, S. (2020). Lebanon's waste crisis worsens amid COVID-19 outbreak. Retrieved from https://www.al-monitor.com/pulse/originals/2020/04/lebanon-medical-waste-crisis coronavirus.html

Azzi, E. (2017). Waste Management Systems in Lebanon: The benefits of a waste crisis for improvement of practices (Degree Project In The Field Of Technology Civil Engineering And Urban Management And The Main Field Of Study The Built Environment, KYH Royal Institute of Technology). https://www.diva-portal.org/smash/get/diva2:1139992/FULLTEXT01.pdf

Bahl, R., Miner, J. \& Schroeder, L. (1984). Mobilizing local resources in developing countries. Public Administration and Development, 4(3), 215-230.

Boswall, J. (2019). Lebanon: the state of waste. Heinrich Boll Stiftung. http://www.lb.boell.org/sites/default/files/2019-12/lebanon_the_state_of_waste_1.pdf

Cramer, J. M. (2020). Practice-based model for implementing circular economy: The case of the Amsterdam Metropolitan Area. Journal of Cleaner Production, 255, 120255.

Dobers, P. \& Halme, M. (2009). Corporate social responsibility and developing countries. Corporate Social Responsibility and Environmental Management, 16(5), 237-249.

Dolinsky, M. \& Maier, S. (2015). Market-based approach in shift from linear economy towards circular economy supported by game theory analysis. Creative and Knowledge Society, 5(2), 1.

Geissdoerfer, M., Savaget, P., Bocken, N. M. \& Hultink, E. J. (2017). The Circular Economy-A new sustainability paradigm?. Journal of Cleaner Production, 143, 757-768.

Geng, Y. \& Doberstein, B. (2008). Developing the circular economy in China: Challenges and opportunities for achieving "leapfrog development". The International Journal of Sustainable Development \& World Ecology, 15(3), 231-239.

George, D. A., Lin, B. C. A. \& Chen, Y. (2015). A circular economy model of economic growth. Environmental modelling \& software, 73, 60-63.

Govindan, K. \& Hasanagic, M. (2018). A systematic review on drivers, barriers, and practices towards circular economy: a supply chain perspective. International Journal of Production Research, 56(1-2), 278-311.

Hu, Y., He, X., \& Poustie, M. (2018). Can legislation promote a circular economy? A material flow-based evaluation of the circular degree of the chinese economy. Sustainability, 10(4), 990.

Kirchherr, J., Reike, D. \& Hekkert, M. (2017). Conceptualizing the circular economy: An analysis of 114 definitions. Resources, Conservation and Recycling, 127, 221-232.

Lewandowski, M. (2016). Designing the business models for circular economy - Towards the conceptual framework. Sustainability, 8(1), 43.

Loorbach, D. (2010). Transition management for sustainable development: a prescriptive, complexity-based governance framework. Governance, 23(1), 161-183.

Lüdeke-Freund, F., Gold, S. \& Bocken, N. M. (2019). A review and typology of circular economy business model patterns. Journal of Industrial Ecology, 23(1), 36-61.

Mavropoulos, A. (2017). Lebanon Waste Crisis: how it all started. Retrieved from https://wastelessfuture.com/lebanese-waste-crisis-how-it-all-started/

Oliveira, F. R. D., Santos, R. F. D., França, S. L. B. \& Rangel, L. A. D. (2020). Strategies and Challenges for the Circular Economy: a Case Study in Portugal and a Panorama for Brazil. Brazilian Archives of Biology and Technology, 63. 
Reike, D., Vermeulen, W. J. \& Witjes, S. (2018). The circular economy: new or refurbished as CE 3.0? - exploring controversies in the conceptualization of the circular economy through a focus on history and resource value retention options. Resources, Conservation and Recycling, 135, 246-264.

Rizos, V., Behrens, A., Van der Gaast, W., Hofman, E., Ioannou, A., Kafyeke, T. et al. (2016). Implementation of circular economy business models by small and medium-sized enterprises (SMEs): Barriers and enablers. Sustainability, 8(11), 1212.

Romboli, A., Stella, C., Kerbage, M., Tackchi, Y., Eikelenboom, M., Kostanian, A. et al. (2018). The Lebanon municipal solid waste crisis and pathways forward. Arthur D. Little. https://www.adlittle.mx/sites/default/files/viewpoints/adl_the_lebanon_municipal_solid_waste _crisis_and_possible_pathways_forward-compressed_0.pdf

Sariatli, F. (2017). Linear Economy versus Circular Economy: A comparative and analyzer study for Optimization of Economy for Sustainability. Visegrad Journal on Bioeconomy and Sustainable Development, 6(1), 31-34.

Schroeder, P., Anggraeni, K. \& Weber, U. (2019). The relevance of circular economy practices to the sustainable development goals. Journal of Industrial Ecology, 23(1), 77-95.

Wautelet, T. (2018). Exploring the role of independent retailers in the circular economy: a case study approach (Master Thesis, European University for Economics \& Management). Researchgate.

https://www.researchgate.net/publication/323809440_Exploring_the_role_of_independent_reta ilers_in_the_circular_economy_a_case_study_approach

WOIMA. (n.d.). Drowning In Waste - Case Beirut, Lebanon, Retrieved from https://woimacorporation.com/drowning-in-waste-case-beirut-lebanon/

Wright, G. \& Czelusta, J. (2003). Mineral resources and economic development. Paper presented at the Conference on Sector Reform in Latin America. Stanford, CA.

Zink, T. \& Geyer, R. (2017). Circular economy rebound. Journal of Industrial Ecology, 21(3), 593602. 